\title{
Nombres y rótulos étnicos en la región pampeana durante la segunda mitad del siglo XVII
}

Q Sabrina Lorena Vollweiler*

Fecha de recepción: 7 de junio de 2019. Fecha de aceptación: 22 de abril de 2020

Palabras clave

pampas

serranos

río Cuarto

Buenos Aires

\section{Resumen}

Los pueblos originarios que habitaban la región pampeana de la actual Argentina durante la colonia fueron descritos por religiosos, funcionarios de la corona española, vecinos y encomenderos, entre otros. En base a sus propias cosmovisiones e intereses, esos agentes coloniales registraron diversos aspectos de los grupos indígenas que habitaron entre el sur de la ciudad de Córdoba y las cercanías de Buenos Aires en las últimas décadas del siglo XVII. En este trabajo nos centramos en los territorios habitados por los grupos indígenas y en los desplazamientos -voluntarios y forzados- por ellos realizados con el objetivo de analizar a qué caciques y grupos hacen referencias los rótulos de "pampas" y "serranos".

Names and ethnic labels in the Pampa region, during the second half of the 17th Century

\footnotetext{
Abstract

Key words

Pampas

Serranos río Cuarto River Buenos Aires

The indigenous population that lived in the pampa region, current Argentine Republic, was described by religious representatives, colonial government officials, neighbors, encomenderos and others. Based on their own worldview and interests, they recorded different aspects of the indigenous groups living in the area located between south of Córdoba and Buenos Aires city during the late 17th Century. In this paper we focus on the territory in which the indigenous groups lived and their displacements -voluntary and forcedaiming to analyze which chiefs and groups are referred to with the ethnic labels "pampas" and "serranos".
}

\footnotetext{
* Centro de Investigaciones Sociales - Consejo de Investigaciones Científicas y Técnicas (CONICET) /Instituto de Desarrollo Económico y Social (IDES). Ciudad Autónoma de Buenos Aires (CABA), Argentina. E-mail: vollweiler. sabrina@gmail.com
} 


\section{Introducción}

La región pampeana se extiende en el extremo sur del continente americano, entre el Río de la Plata y la costa del océano Atlántico, por el este, y aproximadamente hasta los $67^{\circ}$ de longitud hacia el oeste y entre los paralelos de $32^{\circ}$ y $40^{\circ}$ de latitud sur (Nacuzzi, 2016). En la época colonial, se destacaban en esta región la ciudad de Buenos Aires -localizada junto al mencionado ríoy hacia el norte la ciudad de Córdoba. Desde ambas, los agentes coloniales interactuaron con los grupos indígenas próximos, entre otras formas, a partir de la ejecución de expediciones y malocas así como del establecimiento de encomiendas y reducciones en los alrededores de las ciudades. Por este motivo, en los ámbitos administrativos y religiosos de Córdoba y de Buenos Aires se confeccionaron documentos que contienen información acerca de los pueblos originarios de esa región.

En este trabajo nos centraremos en los grupos indígenas denominados en las fuentes de manera genérica como "pampas" y "serranos". ${ }^{1}$ Ambas categorías respondieron a los intereses y necesidades de los colonizadores y no a identidades propias de los grupos (Nacuzzi, 1998; Boccara, 2002). Con el objetivo de analizar qué se entendía por pampas y por serranos en ese contexto y dónde se localizaban, seguiremos el modelo de análisis propuesto por Nacuzzi (1998) por lo que nos centraremos en los nombres de sus caciques y los grupos a los que respondían y representaban. La indagación en el derrotero de los caciques y sus seguidores nos permitirá identificar algunas correspondencias entre los grupos indígenas que circularon entre el sur de la ciudad de Córdoba -en la zona del río Cuarto- y las inmediaciones de Buenos Aires. Observaremos cómo, en algunas ocasiones, los rótulos de pampas y de serranos fueron intercambiables en función de los grupos en cuestión y de las necesidades de aquellos funcionarios o misioneros que emplearon esas categorías. De esta forma, los pueblos originarios de la llanura pampeana fueron denominados alternativamente de una u otra manera sin que ello implicara algún tipo de reconocimiento de sus adscripciones étnicas.

Si bien algunos fueron encomendados y reducidos en más de una ocasión, la mayor parte del tiempo permanecieron insumisos a las autoridades coloniales ya que las estrategias de conquista y colonización no obtuvieron resultados satisfactorios en la región. En este trabajo analizaremos un escrito elaborado por el padre Francisco Lucas Caballero ${ }^{2}$ (1661-1711) en el que narra los viajes emprendidos desde la ciudad de Córdoba hacia el río Cuarto entre los años 1689 y 1692 donde se encontraban algunos grupos indígenas por él denominados pampas. ${ }^{3}$ El relato de los encuentros y conversaciones entre el jesuita y los caciques nos permite conocer, entre otros aspectos, los parajes por los que solían desplazarse, sus preocupaciones cotidianas, los parentescos entre ellos y las enemistades con otros caciques y grupos. Asimismo, incluiremos en el análisis datos de los registros que se conservan acerca de algunos grupos denominados pampas y otros como serranos, unos de ellos encomendados en Córdoba y otros reducidos en Buenos Aires. ${ }^{4}$ De esta manera, nos proponemos conocer con mayor precisión quiénes eran sus caciques, en qué territorios se encontraban y cómo se relacionaban con los agentes de la colonia.

\section{La región pampeana}

Durante el siglo XVII y hasta 1776, la llanura pampeana formaba parte del Virreinato del Perú que se extendía desde la zona central de América hasta
1. Omitiré el empleo de comillas en las menciones a los grupos "pampas" y "serranos" a lo largo del trabajo.
2. Caballero fue un misionero español que se embarcó a América en 1680 y, una vez arribado al continente, se dirigió hacia Córdoba. Al finalizar sus estudios eclesiásticos, emprendió una salida hacia los ríos Tercero y Cuarto en el año 1689 en la cual entabló conversaciones con el cacique Ignacio Muturo. Para más información de la experiencia de Caballero en el río Cuarto ver Page (2006 y 2007) y Simonassi (2016).

3. La transcripción del documento consultado para este trabajo ha sido publicada por Carlos A. Page (2007). El autor consultó el manuscrito del Archivo General de la Nación (en adelante AGN), leg. 189, doc. 1845, fs. 88-107; además, existe una copia manuscrita en la Biblioteca Nacional de Río de Janeiro, rollo 36, doc. 1093, im. 399 a 447.

4. Estas fuentes documentales se conservan en el AGI (Sevilla, España) y sus copias se hallan en la biblioteca del Museo Etnográfico "Juan B. Ambrosetti" de la Facultad de Filosofía y Letras, Universidad de Buenos Aires (Buenos Aires, Argentina). 
5. En 1617 la gobernación del Río de la Plata fue dividida en dos: la gobernación del Río de la Plata, donde quedó incluida Buenos Aires junto con otras ciudades, y la de Guairá -gobernación del Paraguay(Assadourian et al., 2005).
6. La cédula de la encomienda de Gerónimo Luis de Cabrera sobre dos grupos indígenas de la ciudad de Córdoba -los pueblos del valle de Quilino y alrededores y los indios del valle de Camincosquines del 24 de noviembre de 1573 . Además, Cabrera otorgó mercedes de tierras y de encomiendas a otros integrantes de la hueste conquistadora y a vecinos de la ciudad (Castro Olañeta, 2005).

7. Aunque el número de trabajadores en cada estancia dependía de la extensión y existencia de ganado en cada una de ellas, Assadourian (1982: 42) sostiene que, en general, estaba compuesta por un mayordomo y de 2 a 10 peones mientras que la del río Cuarto, la mayor de Córdoba, ocupaba "entre 1672 y 1683 un promedio anual de 22 peones". la parte más austral del continente. Las ciudades de Buenos Aires -fundada en 1536 por Pedro de Mendoza y nuevamente en 1580 por Juan de Garay- y de Córdoba -fundada en 1573 por Jerónimo Luis de Cabrera- se destacaban en esa región; la primera formaba parte de la gobernación del Río de la Plata ${ }^{5}$ y la segunda de la del Tucumán. En 1663 se instaló la Audiencia de Buenos Aires en la gobernación del Río de la Plata y, unos años más tarde, la ciudad de Buenos Aires fue constituida en capital de esa gobernación (Assadourian et al., 2005). A diferencia de los grupos indígenas, quienes accedían a la región pampeana desde diversos lugares, los agentes coloniales se adentraban en el territorio desde Buenos Aires y Córdoba, así como desde la ciudad de Mendoza -que formaba parte de la región de Cuyo del reino de Chile en ese entonces.

Los gobernadores respondían a la autoridad monárquica al relacionarse con los sectores locales para lo cual desplegaron una política de consenso y negociación. Sin embargo, la lejanía de Buenos Aires en tanto centro administrativo respecto de España y de otros puntos de la América española implicó una flexibilidad en la aplicación de las disposiciones reales que favoreció la acumulación de poder en tanto directos representantes de la corona (Lorandi, 2008; Trujillo, 2014). En el área y el período aquí analizados observamos cómo las encomiendas, las reducciones y los pueblos de indios, entre otras instituciones implementadas por los gobiernos de Córdoba y de Buenos Aires, adoptaron formas más laxas en comparación de aquellas dispuestas en el Alto Perú ya que, según Palomeque (2000), las políticas generales de la corona no lograron ser impuestas por las autoridades virreinales.

En el aspecto económico, los efectos de arrastre de la producción argentífera de Potosí alcanzaron las áreas tucumana y rioplatense (Fradkin y Garavaglia, 2009). La producción de Córdoba -en tanto parte de la gobernación de Tucumán- fue variando a lo largo del tiempo en función de la demanda del mercado minero: del cultivo de algodón durante el siglo XVI y parte del XVII sus productores se abocaron al sector ganadero hacia fines de esa centuria (Assadourian, 1982). Desde otras regiones del Tucumán y del Río de la Plata se exportaron vacunos hacia Potosí y, con el paso del tiempo, la necesidad de un animal de carga para trasladar mercancías volcó a Córdoba hacia la producción mular, actividad principal de la región hasta mediados del siglo siguiente (Assadourian, 1982).

Hacia el sur de la ciudad, en el río Cuarto, la familia Cabrera poseyó estancias en las que encomendaron a algunos grupos indígenas. ${ }^{6}$ Cabrera acompañó los cambios en la actividad económica a lo largo de las décadas: pasó del cultivo de algodón en el obraje de La Lagunilla a la producción de ovejas en su estancia de San Lorenzo y luego a la cría de mulas y vacas en los terrenos de San Blas de la Sierra (Assadourian, 1982). ${ }^{7}$ Asimismo, Buenos Aires y Santa Fe también se convirtieron en regiones productoras de gran envergadura durante el siglo XVII. Según Fradkin y Garavaglia (2009), Buenos Aires se destacó en el contrabando y en el tráfico directo -de esclavos y de mercancías europeas- además de la actividad ganadera y agrícola y, según Salles y Noejovich (1999), luego de algunas décadas de altibajos, la economía bonaerense se recuperó hacia la segunda mitad del siglo XVII. Las actividades económicas desarrolladas en estas zonas necesitaron de la mano de obra de la población indígena, por lo que diversos agentes coloniales implementaron variadas estrategias con el objetivo de controlarla y reducirla.

En las cercanías de Buenos Aires, algunos de los grupos indígenas que habitaban esos parajes fueron repartidos en encomiendas concentradas en 
reducciones a principios del siglo XVII: el cacique Bagual fue llevado a Areco, el cacique Tubichaminí a la costa del Río de la Plata, y el cacique guaraní Don Bartolomé a la del arroyo Baradero. ${ }^{8}$ El objetivo de estas reducciones fue asegurar la obtención de mano de obra -en la ciudad y las estancias circundantes- y evangelizar a la población indígena (Carlón, 2006). Sin embargo, las huidas hacia la tierra adentro fueron frecuentes para gran parte de los grupos reducidos en parajes cercanos a las ciudades, pese a que podían volver a ser capturados y relocalizados. ${ }^{9}$ De esta manera, los funcionarios coloniales encontraban una justificación para ejecutarlas malocas y expediciones hacia la tierra adentro con el objetivo de aprehender a los grupos indígenas y continuar con el establecimiento de encomiendas y reducciones.

Como estrategia complementaria, también procuraron alejar de la ciudad de Buenos Aires y su campaña a una gran cantidad de grupos indígenas que no les interesaba reducir. Para lograr eso, se basaron en "intimar u ordenar a los grupos indígenas que se mantuvieran en sus territorios, por fuera de las jurisdicciones hispanocriollas" (Nacuzzi y Tourres, 2018: 38). Según Bechis (2008b), en 1659 el río Salado, hacia el sur de Buenos Aires, fue definido como un límite para los grupos serranos que no debían cruzar ese curso de agua. Según Nacuzzi (2014), el establecimiento de este límite constituía una formulación ideal ante la falta de fuerzas militares o pobladores que pudieran ocupar efectivamente las tierras y buscó establecer un ordenamiento territorial que procuraba evitar la presencia de grupos indígenas libres en las inmediaciones de la ciudad.

En efecto, la potencial proximidad de los pueblos originarios despertaba temores en los funcionarios coloniales y los habitantes de poblados y ciudades. Similares situaciones ocurrían en las inmediaciones de los caminos que conectaban Buenos Aires con Córdoba, Mendoza o Chile (Roulet, 2018) por lo que la región era poco frecuentada por los hispanocriollos. En general, se adentraban allí en sus vaquerías con el objetivo de obtener ganado cimarrón, para transportar mercadería entre ciudades y para apresar a grupos indígenas con pretextos varios y luego reducirlos y encomendarlos. Si bien algunos grupos indígenas habían vivido experiencias reduccionales como consecuencia de las malocas, fueron en su mayoría esporádicas y efímeras, por lo que constituían grupos mayoritariamente libres e insumisos a la agencia colonial. A continuación, nos centraremos en los registros de la población indígena de la región por parte de los agentes coloniales.

\section{"Pampas" y "serranos" en las fuentes documentales}

Los reiterados esfuerzos para controlar a la población indígena de la región pampeana conllevaron un proceso de aproximación y conocimiento de estas sociedades. En líneas generales, primaban las apreciaciones basadas en los intereses y necesidades de la colonia; a lo largo de los años, los diversos registros confeccionados crearon un panorama aproximado de los grupos indígenas. En este trabajo nos centraremos en los rótulos empleados para denominar a los grupos indígenas de la llanura pampeana en el siglo XVII: algunos los llamaban pampas -entre ellos Caballero, el jesuita que desde la ciudad de Córdoba se adentró hacia el río Cuarto- mientras que otros los designaban serranos -por ejemplo, algunos funcionarios desde Buenos Aires.

Entendemos que las denominaciones empleadas para identificar a los pueblos originarios respondían a los fines de los agentes coloniales y no a
8. Para un análisis del derrotero de las tres reducciones ver Carlón (2006) y para el del pueblo de indios de Santiago del Baradero ver Tapia et al. (2015).

9. Al analizar las respuestas de los grupos indígenas a la violencia colonial Roulet (2018) observó que las oposiciones habituales eran representadas con huidas hacia la tierra adentro, facilitadas por el hecho de que muchos permanecieron próximos a sus tierras de origen en las ocasiones en las que eran capturados y relocalizados en las cercanías de la ciudad. 
10. Según Bartolomé (2003), la categoría de etnogénesis alude al dinamismo de los grupos étnicos, a sus lógicas sociales, las cuales revelan una gran capacidad de adaptación. Así, posee variadas acepciones utilizadas para estudiar estos procesos en el presente y en el pasado: apunta a los procesos de reemergencia étnica y al surgimiento o resurgimiento de grupos étnicos en la actualidad (Bartolomé, 2006). También, es utilizada "para dar cuenta del proceso histórico de la configuración de colectividades étnicas, como resultado de migraciones, invasiones, conquistas o fusiones" (Bartolomé, 2003: 174). Y aunque este término ha recorrido distintos caminos en la actualidad en relación con los procesos de reemergencia étnica, en este trabajo será utilizado en perspectiva histórica. denominaciones propias de los grupos en cuestión. Según Nacuzzi (1998), se trataba de identidades impuestas por los agentes coloniales que utilizaban sobre todo categorías basadas en la ubicación geográfica de los grupos indígenas así como sus relaciones con otros. Al rotular a los sujetos con los que interactuaban su interés no estaba centrado en "delimitar grupos y naciones, sino [en] hacer posible la convivencia y el trato con ellos. Con este fin, sólo necesitaban identificarlos de alguna manera" (Nacuzzi, 1998: 133). Estas definiciones identitarias sufrieron modificaciones a través del tiempo por lo que, siguiendo a Boccara (2002), debemos atender a las capacidades de adaptación y de creación de los grupos étnicos que devinieron en procesos de etnogénesis -transformaciones políticas e identitarias en un grupo a través del tiempo en base a sus definiciones internas y las categorizaciones externas- así como de etnificación -creación de entidades étnicas a semejanza de las concepciones de los agentes colonizadores. ${ }^{10}$ Según el autor, la diferenciación en diversos grupos étnicos debe ser entendida como producto de una historia en la cual participaron tanto las sociedades indígenas como el poder colonial.

En estos mismos sentidos, Giudicelli (2007) sostiene que las clasificaciones que encontramos en los documentos son construidas ya que expresan el accionar de los agentes coloniales quienes, interesados en circunscribir y empadronar en base a sus necesidades, brindaron una visión compartimentada de la sociedad indígena. Por lo tanto, frente a los cambios de lugares o de roles dentro del espacio controlado por los funcionarios de la colonia podían modificarse también las adscripciones y los nombres atribuidos a los grupos y a sus integrantes. Siguiendo el planteo del autor, "se trataría ya no de individuar una serie de unidades aisladas, sino de asir la articulación sociopolítica fluida que los pone en continuidad debajo de la adscripción colonial" (Giudicelli, 2007: 206).

Siguiendo estas perspectivas, aquí nos proponemos reconstruir las articulaciones de los grupos étnicos de la llanura pampeana más allá de los rótulos empleados para circunscribirlos en cada ocasión. Para ello, seguiremos el modelo de análisis propuesto por Nacuzzi (1998): prestaremos atención a los nombres de los grupos y de sus caciques, así como a los parajes y territorialidades registrados como propios de cada uno de ellos. Estos caciques fueron identificados con distintos nombres y reconocidos como pertenecientes a grupos mayores por lo que, luego de un rastreo de sus denominaciones, analizaremos el empleo de los rótulos pampas y serranos por parte de quienes los registraron.

Según Pedrotta (2005), ambas designaciones fueron utilizadas a partir del siglo XVII para aludir a las sociedades indígenas de la región pampeana en relación con el ambiente. "Los pampas habitaban las campañas más próximas a Buenos Aires y constituyeron el objetivo principal de las incursiones españolas en busca de indígenas para ser encomendados y reducidos durante el siglo XVI" (Pedrotta, 2005: 125). Durante la segunda mitad del siglo XVII y la primera del XVIII habrían primado dos acepciones: en base a un criterio geográfico centrado en Buenos Aires para referirse los grupos procedentes del sur y del oeste que frecuentaban las llanuras pampeanas para explotar ganado vacuno y caballar y, con un sentido más restringido, para aludir a aquellos "vinculados laboral y comercialmente con las estancias y poblados hispano-criollos" (Pedrotta, 2005: 126). Por otro lado, se denominaba como serranos a aquellos que habitaban lugares más alejados que las pampas: las sierras de San Luis, Córdoba, los cordones serranos boanerenses y/o la cordillera andina. 
Por su parte, Roulet (2016) también sostiene que para diferenciar a los pampas de los serranos se construyó un criterio geográfico que distinguía a los grupos que vivían en las llanuras, denominados pampas, de aquellos que vivían o procedían de regiones montañosas, los serranos. Según la autora, hubo una continuidad histórica entre los denominados querandíes y guaraníes de los primeros tiempos de la conquista en Buenos Aires y aquellos conocidos como pampas, probada por las listas de los caciques y sus seguidores encomendados en la misma ciudad durante el siglo XVII. Los serranos, por su parte, provendrían de los Andes y de las sierras al sur de Buenos Aires -los sistemas de Tandilia y Ventania-, así como de los ríos Colorado y Negro. Sin embargo, en los primeros años del siglo XVIII el rótulo pampa se modificó nuevamente porque fueron rebautizados como pampas también los habitantes de las serranías de Tandilia y Ventania, "aunque a veces se precisaba que se trataba de pampas serranos" (Roulet, 2016: 63). ${ }^{11}$

A continuación, analizaremos diversos nombres y rótulos empleados para denominar a los grupos indígenas y sus caciques en la región pampeana: en el sur de Córdoba y en los alrededores de la ciudad de Buenos Aires. Nos proponemos conocer algunos ejemplos de los itinerarios seguidos por los grupos étnicos llamados alternativamente pampas y serranos en la segunda mitad del siglo XVII y, para eso, seguiremos los nombres asignados a sus caciques. Nos basaremos en las denominaciones utilizadas por el jesuita Caballero en el río Cuarto y por los funcionarios coloniales en Buenos Aires en relación con los territorios en los que se encontraban los grupos indígenas en cuestión, así como con aquellos lugares en los que habían estado previamente.

\section{Los caciques: nombres y desplazamientos}

En la zona del río Cuarto -en el paraje del Espinillo, cercano a Punta del Sauceentre 1689 y 1692 vivieron los caciques Ignacio Muturo, Pascual, Manuel, Jacinto, Bravo, Sanemte y Jaime. ${ }^{12}$ Ellos fueron los interlocutores del jesuita Francisco Lucas Caballero en distintos momentos de los cinco viajes que realizó desde la ciudad de Córdoba hacia el río Cuarto, para emprender una reducción junto con su compañero Fermín Calatayud. En el escrito que redactó al finalizar la experiencia reduccional denominó a los integrantes de los grupos con los que había interactuado de manera genérica como pampas y registró información de los pensamientos y estrategias de algunos de ellos por lo que podemos aspirar a reconocer con mayor precisión sus grupos de pertenencia. En el primer viaje al río Cuarto, Caballero identificó el lugar a donde había llegado -cercano a Punta del Sauce- como Mula Corral, perteneciente a la hacienda de Jerónimo Luis de Cabrera (Page, 2007). A partir del segundo viaje, mencionó el puesto del Espinillo como el lugar en donde se encontraban algunos caciques, paraje que sería elegido para instalar la reducción.

Si nos remontamos unas décadas atrás, según Pérez Zavala y Tamagnini (2012: 202), en la primera mitad del siglo XVII se hallaban algunos "indios pampas reducidos junto con comechingones en la encomienda del general Gerónimo de Cabrera y sus sucesores, conocida también como 'Encomienda del Río $4^{\circ \prime \prime \prime}$. Asimismo, Roulet (2016: 58, las cursiva son del original) sostiene que "en los primeros tiempos de la conquista los pobladores nativos de las sierras y valle de Calamuchita fueron llamados comechingones" y "naures, hablantes de la lengua camiare". Según Barrionuevo Imposti (1986: 10), a principios del siglo XVII, muchos de los grupos indígenas denominados muturos "fueron
11. Bechis (2008a) analiza unos documentos que reflejan los conflictos interétnicos por el ganado cimarrón a principios del siglo XVIII en los que se acusa a algunos caciques de haber cometido asaltos y muertes a tropas de vaqueros. Se pregunta si realmente los pampas habían sido los autores de todos los asesinatos que se les atribuían y concluye que "los asesinos de las tres tropas nombradas no fueron pampas sino gente del pie de la cordillera o que, cuando mucho, había sido una coparticipación de los pampas. [...] Esto probaría la esterotipia social dominante hasta, por lo menos, octubre de 1710 tal vez producto del desconocimiento de la época" (Bechis, 2008a: 65). $\mathrm{Si}$ atendemos a las categorías de Boccara (2003), estaríamos ante un caso de etnificación combinado con un proceso de etnización, donde la realidad social y política es leída a partir de un prisma étnico-cultural y racial.

12. Los caciques con nombres hispanos -Ignacio, Pascual, Manuel y Jacinto- fueron mencionados con la categoría de "don" antes de sus nombres en todo el escrito, probablemente en reconocimiento de su calidad de líderes. 
13. Archivo General de Indias (en adelante AGI). Audiencia de Charcas (en adelante $\mathrm{ACH}$ ), Leg. 284, carta de Don Andrés de Robles, Buenos Aires, 06/12/1677. Hay copia en el Museo Etnográfico (en adelante ME), carpeta $F$, doc. 5. En las transcripciones utilizadas se modernizó la ortografía y se desplegaron las abreviaturas.

14. AGI. ACH, Leg. 284, carta de Don Andrés de Robles al Rey, Buenos Aires, 08/12/1677. Hay copia en el ME, carpeta $\mathrm{F}$, doc. 5 .

15. Los caciques mencionados también fueron registrados con la categoría de "don" antes de sus nombres hispanos en esta oportunidad. atrapados en el río Quinto y reducidos por los encomenderos en sus estancias de los ríos Tercero y Cuarto".

El jesuita Caballero se refirió al cacique Ignacio Muturo como "cacique principal". Este cacique podría haber formado parte -él o miembros de su grupo- de aquellos individuos del río Quinto denominados unas décadas atrás como muturos y encomendados junto a los del río Cuarto. Esto daría un indicio de la territorialidad y movilidad del grupo, ya fuera por interés propio o debido a traslados forzados de agentes externos como podrían haber sido los encomenderos de la zona. Ignacio Muturo era pariente del cacique Bravo, quien había arribado desde la tierra adentro y también tenía como primo al cacique Manuel, por lo que al menos tres de los caciques mencionados por Caballero estaban emparentados entre sí.

En la segunda mitad del siglo XVII, caciques denominados Ignacio y Bravo fueron registrados juntos en más de una oportunidad. Por ejemplo, en 1677, con el pretexto de unos robos cometidos por algunos indígenas, Manuel de Robles emprendió una expedición que se dirigió a "la vuelta de la sierra por el paraje de Melincué" donde apresó a "ciento trece personas de todos sexos y edades".${ }^{13}$ Unos días más tarde, a fines de ese año, se confeccionó un padrón en la ribera del Río de la Plata en la ciudad de Buenos Aires con una división de los grupos en base a sus caciques. Entre los empadronados figuraban Ignacio, Jacinto -"natural de Pampallatad en Córdoba y cacique de la encomienda que fue de Alonso Díaz Caballero y hoy es de Gregorio Díaz"-, Manuel Flaco -"hijo de Don Juan Flaco encomendado o depositado en el capitán Sebastián Crespo" ${ }^{14}$ y Bernabé Serrano. ${ }^{15}$ Además, algunos indígenas habían sido asentados como pertenecientes a la encomienda de Gerónimo Luis de Cabrera. Así, observamos que del total de apresados en las cercanías de Melincué y trasladados hacia Buenos Aires, muchos habían estado encomendados previamente en Córdoba, como se menciona en el padrón.

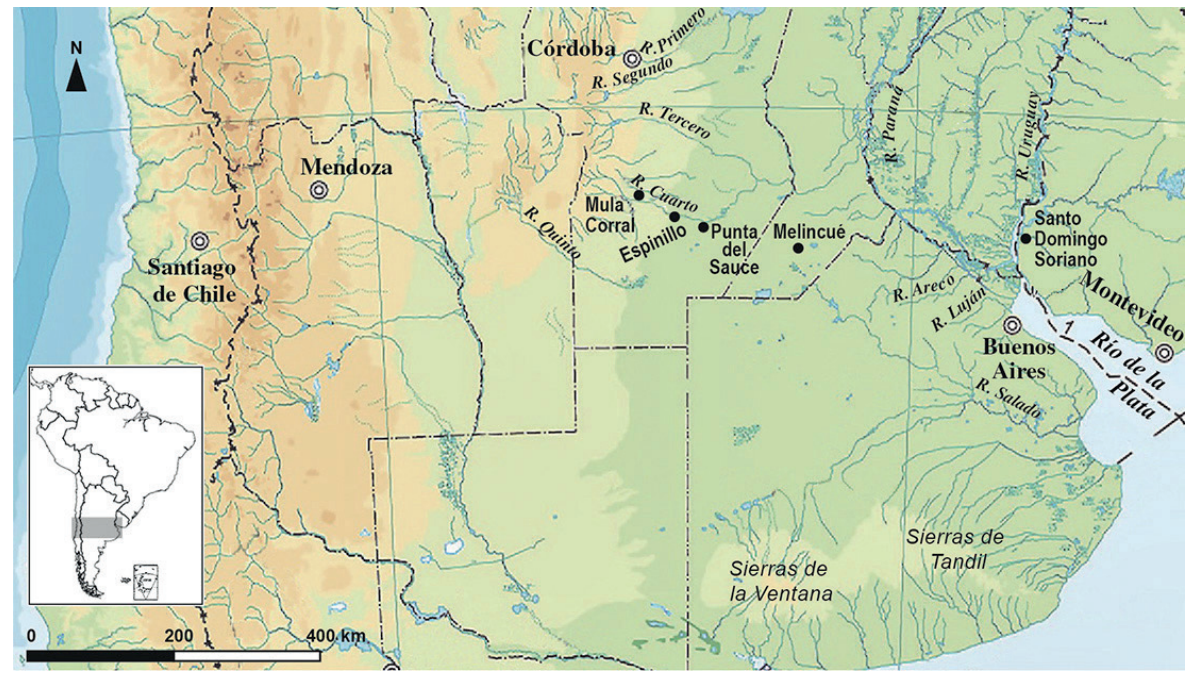

Mapa 1. Las Pampas, Nor-Patagonia y Cuyo. Elaboración propia.

Al observar los parajes referidos (mapa), notamos algunos de los sucesivos desplazamientos -tanto voluntarios como forzados- emprendidos por estos grupos. En primer lugar, al encomendar algunos grupos del río Quinto junto con los de los ríos Tercero y Cuarto, algunos individuos fueron llevados hacia el norte. Luego, algunos de los que escaparon de las encomiendas de Córdoba se dirigieron hacia Melincué -al sudeste de la ciudad- en donde fueron 
apresados por las autoridades bonaerenses y nuevamente desplazados más hacia el sudeste, a las cercanías de la ciudad de Buenos Aires, en donde se encontraban a fines de 1677.

En marzo del siguiente año, 1678, los funcionarios coloniales organizaron otro registro ya no en función de los caciques y sus seguidores sino en base a las encomiendas a las que estaban asignados. En este nuevo padrón y ordenamiento respetaron algunas cuestiones como por ejemplo la organización familiar -los matrimonios y su descendencia- pero redistribuyeron a algunos individuos y los reagruparon con algunos otros. Según Giudicelli (2007: 175, cursiva en el original), era habitual que los indígenas figurasen en los títulos de encomienda como "pueblos y parcialidades y representados por uno o varios caciques" que pudieran ocupar un puesto de autoridad. En efecto, los caciques Manuel Flaco e Ignacio Jalamelec ${ }^{16}$ habían sido entregados junto con sus seguidores en merced al capitán Sebastián Crespo Flores, Bernabé -registrado como "cacique serrano"- en encomienda a Gerónimo Luis de Cabrera y el cacique Jacinto a Gregorio Diaz, vecino de Córdoba.

Asimismo, se empadronó a un cacique llamado Nusanash o Bravo que había sido apresado o se había ido a entregar por su propia voluntad debido a un conflicto con otros grupos. El escrito expresa las dos variantes: que "dicho cacique se venía a entregar y amparar de los españoles por los daños que de otro cacique que asiste en el río que llaman de los Sauces [Negro]" y, a su vez, que "por la parte del sur de la otra banda del Saladillo [Salado] se apresó al cacique llamado el Bravo con treinta o treinta y una personas de todas edades y sexos". ${ }^{17 .}$ Además, se había acercado junto con otro cacique llamado de la misma manera -quien murió- y los individuos que los acompañaban. Todos ellos, quienes "nunca habían bajado de la sierra, ni visto a los Españoles", fueron identificados como "de nación serranos" ${ }^{18}$ Bravo fue trasladado a la reducción de Santo Domingo Soriano -treinta leguas al norte de la ciudad de Buenos Aires.

Unos años más tarde, en 1686, Bravo "con sus vasallos se ha reconocido estaban reducidos a paz y quietud y encaminados al cumplimiento de nuestra santa fe católica" ${ }^{\prime 19}$ en esa reducción, a diferencia de dos caciques que habían sido recientemente trasladados. Se trataba de Ignacio y Sacaperu, quienes habían sido apresados a dieciocho leguas de Buenos Aires en una maloca junto con doscientas personas "de todas edades, y sexos", ${ }^{20}$ llevadas al puerto de la ciudad y luego relocalizadas en Santo Domingo Soriano. El objetivo era que quedaran "desnaturalizados, a imitación de otros que se hallaban en ella". ${ }^{21}$ Sin embargo, al poco tiempo de haber sido desplazados por la fuerza realizaron una matanza de los españoles que allí se encontraban y lograron escapar.

Encontramos los nombres Ignacio, Manuel, Jacinto y Bravo tanto en la documentación elaborada en Buenos Aires desde fines de 1677 como en los diarios del jesuita Caballero de una década más tarde, a fines de 1680 y comienzos de 1690 (cuadro 1). En el caso de Bravo, sabemos que en 1677 llegó desde la Patagonia, del "río de los Sauces" [Negro] a Buenos Aires y fue trasladado a Santo Domingo Soriano en 1678 donde permaneció al menos hasta 1686. El nombre "Bravo" insinuaba algunas características de su personalidad y su comportamiento, seguramente se refería a su valentía y ferocidad; fue un nombre utilizado por muchas décadas para denominar a distintos caciques. ${ }^{22}$ Por lo tanto, las menciones de la segunda mitad del siglo XVII registradas en los documentos aquí analizados podrían aludir tanto a un mismo individuo como a sujetos distintos con un mismo nombre.
16. Se trata del mismo cacique en los padrones de 1677 y 1678 , en ambos acompañado de su mujer y su hijo. A diferencia de 1677 donde se lo registró como Ignacio, en 1678 fue anotado como Ignacio Jalamelec "con los de su parcialidad y nación Jalamelec”. AGI. ACH, Leg. 284, carta de Don Andrés de Robles, Trinidad y Puerto de Buenos Aires, $07 / 03 / 1678$. Hay copia en el ME, carpeta F, doc. 5 .

17. AGI. ACH, Leg. 284, carta de Don Andrés de Robles, Buenos Aires, 06/12/1677. Hay copia en el ME, carpeta F, doc. 5 .

18. AGI. ACH, Leg. 284, carta del gobernador Don Andrés de Robles a su majestad, Buenos Aires, 20/04/1678. Hay copia en el ME, carpeta F, doc. 5 .

19. AGI. ACH, Leg. 283, carta de Don José de Herrera y Sotomayor, Ciudad de la Trinidad puerto de Buenos Aires, 24/o8/1686. Hay copia en el ME, carpeta G, doc. 29.

20. AGI. ACH, Leg. 283, carta de Don losé de Herrera y Sotomayor, Ciudad de la Trinidad puerto de Buenos Aires, 05/12/1686. Hay copia en el ME, carpeta G, doc. 29.

21. AGI. ACH, Leg. 283, carta de Don José de Herrera y Sotomayor, Ciudad de la Trinidad puerto de Buenos Aires, 05/12/1686. Hay copia en el ME, carpeta G, doc. 29.

22. Para un análisis del liderazgo de los linajes Bravos en la primera mitad del siglo XVIII, ver Arias (20112012). 


\begin{tabular}{|c|c|c|c|c|c|}
\hline \multicolumn{2}{|c|}{1677 (Melincué-Buenos Aires) } & \multicolumn{2}{|c|}{1678 (Melincué-Buenos Aires) } & \multicolumn{2}{|c|}{ 1689-1692 (Río Cuarto) } \\
\hline Cacique & Encomienda & Encomienda & Cacique & Cacique & Encomienda \\
\hline Jacinto & $\begin{array}{c}\text { “dijo ser natural de } \\
\text { Pampallatad en Córdoba y } \\
\text { cacique de la encomienda } \\
\text { que fue de Alonso Diaz } \\
\text { Caballero y hoy es de } \\
\text { Gregorio Diaz vecino de } \\
\text { Córdoba" } \\
\end{array}$ & $\begin{array}{l}\text { Gregorio Diaz } \\
\text { vecino de } \\
\text { Cordoba }\end{array}$ & $\begin{array}{l}\text { “Don Jacinto } \\
\text { cacique natural de } \\
\text { Pamapallacta }\end{array}$ & Jacinto & José Cabrera \\
\hline $\begin{array}{l}\text { Manuel } \\
\text { Flaco }\end{array}$ & $\begin{array}{l}\text { "hijo de Don Juan } \\
\text { Flaco encomendado o } \\
\text { depositado en el Capitán } \\
\text { Sebastián Flores" }\end{array}$ & $\begin{array}{l}\text { Sebastián Crespo } \\
\text { Flores. } \\
\text { “Fueron de García } \\
\text { Doctor y Antoño } \\
\text { Gomez su hijo” }\end{array}$ & $\begin{array}{l}\text { “Don Manuel Flaco } \\
\text { cacique principal de esta } \\
\text { parcialidad hijo de Don } \\
\text { Juan Flaco que murió" }\end{array}$ & Manuel & José Cabrera \\
\hline Ignacio & $\begin{array}{l}\text { habían "sido de la misma } \\
\text { parcialidad de Don Juan } \\
\text { Flaco padre del dicho } \\
\text { Don Manuel y que por su } \\
\text { muerte de había dividido } \\
\text { sin decir la causa por qué" }\end{array}$ & $\begin{array}{l}\text { Sebastián Crespo } \\
\text { Flores. } \\
\text { “Fueron de García } \\
\text { Doctor y Antoño } \\
\text { Gomez su hijo” }\end{array}$ & $\begin{array}{l}\text { “cacique Don Ygnacio } \\
\text { Jalamelec que con los de } \\
\text { su parcialidad y nación } \\
\text { Jalamelec }\end{array}$ & Ignacio Muturo & $\begin{array}{l}\text { José Cabrera. } \\
\text { En Mula Corral }\end{array}$ \\
\hline \multirow[t]{12}{*}{$\begin{array}{l}\text { Bernabé } \\
\text { Serrano }\end{array}$} & $\begin{array}{l}\text { “dijeron ser de la } \\
\text { encomienda de Don } \\
\text { Gerónimo Luis de } \\
\text { Cabrera”, "dijo haberse } \\
\text { huído su gente” } \\
\end{array}$ & $\begin{array}{c}\text { Don Gerónimo [Luis } \\
\text { de Cabrera] }\end{array}$ & $\begin{array}{l}\text { "a cargo del cacique } \\
\text { serrano Don Bernabe" }\end{array}$ & & \\
\hline & & $\begin{array}{l}\text { SebrianySidro "Fue } \\
\text { de Pedro de Frias" }\end{array}$ & $\begin{array}{c}\text { Juan Caguane, "cacique } \\
\text { principal” }\end{array}$ & & \\
\hline & & María de Salas & $\begin{array}{c}\text { "Parcialidad [...] de nación } \\
\text { Caguane" }\end{array}$ & & \\
\hline & & Felipe Moran & & & \\
\hline & & Antonio Romero & & & \\
\hline & & Pedro de Saavedra & $\begin{array}{l}\text { "Don Pedro Vagual por ser } \\
\text { muerto el cacique Don Juan } \\
\text { Vagual se le reconoce por } \\
\text { cacique por ser su sobrino" }\end{array}$ & & \\
\hline & & $\begin{array}{l}\text { Juan Nieto de } \\
\text { Umanes }\end{array}$ & $\begin{array}{l}\text { "parecieron ser de nación } \\
\text { Caguanes aunque de } \\
\text { diferentes encomiendas } \\
\text { como van excepto la de } \\
\text { Don Juan Vagual" }\end{array}$ & & \\
\hline & & $\begin{array}{l}\text { de Don Gregorio de } \\
\text { Cabrera }\end{array}$ & $\begin{array}{l}\text { “se hallaron entre la } \\
\text { parcialidad de Don Juan } \\
\text { Caguane", "dicen son de la } \\
\text { parcialidad de Don Alonso } \\
\text { cacique" }\end{array}$ & & \\
\hline & & & $\begin{array}{l}\text { "Nusanash cacique Bravo } \\
\text { de nación serrano", "se ha } \\
\text { venido de su voluntad y no } \\
\text { ha sido encomendado" }\end{array}$ & Bravo & $\begin{array}{l}\text { José Cabrera. "cacique } \\
\text { recién venido de la } \\
\text { tierra adentro". En el } \\
\text { Espinillo } \\
\end{array}$ \\
\hline & & & & $\begin{array}{c}\text { Pascual, } \\
\text { “pedía puesto } \\
\text { diferente } \\
\text { desde el } \\
\text { principio", sus } \\
\text { toldos estaban } \\
\text { a dos leguas } \\
\text { del río Cuarto }\end{array}$ & José Cabrera \\
\hline & & & & Sanemte & José Cabrera \\
\hline & & & & Jaime & José Cabrera \\
\hline
\end{tabular}

Cuadro 1. Nombres de los caciques, los parajes y las encomiendas en 1677, 1678 y 1689-92. El cuadro refleja la disposición de los padrones: el de 1677 fue elaborado en base a los caciques y el de 1678 en base a las encomiendas a las que fueron asignados -no se incluyó la cantidad de individuos empadronados en cada caso.. Elaborado en base a las fuentes citadas en el texto. 
Debido a que Santo Domingo Soriano, donde se encontraba el cacique Bravo apresado o entregado en Buenos Aires, quedaba a treinta leguas de esta ciudad -aproximadamente 145 kilómetros- en dirección norte, sobre el río Uruguay, resulta arriesgado suponer que había atravesado los ríos Uruguay y Paraná en dirección oeste, hacia la llanura pampeana, y que se encontraba hacia fines de 1680 en el río Cuarto. Sin embargo, podría ser una posibilidad ya que hay registros del temor de los funcionarios coloniales de que los indígenas que habían formado parte del levantamiento y las muertes en Santo Domingo Soriano hubieran cruzado el río Paraná para "conseguir volver a sus tierras". ${ }^{23}$ Las medidas que tomaron atestiguan esto ya que dispusieron que los buscaran cinco compañías de caballos divididas desde "la boca del río de las Conchas [...] hasta La cañada que llaman de Maldonado, "en la boca del río Luján" hasta "las costas de los ríos de Areco y Palmas", desde "esta parte del dicho río de Luján hasta la boca de las Conchas [río Reconquista]", en "la otra banda del río de Areco hasta el dicho de los Arrecifes y Rincón que llaman de San Pedro" y también desde "la otra banda del rio de los Arrecifes y arroyo de San Pedro hastael paraje que llaman de los Jornillos [sic]". ${ }^{24}$ Aunque no sabemos si Bravo había realizado este recorrido no descartamos esa opción y, en caso de tratarse del mismo cacique que encontró Caballero en el río Cuarto, conoceríamos el itinerario por él seguido unas décadas atrás. Según el jesuita Caballero, Bravo "venía de la tierra adentro", "era libre y no reconocía amo alguno", "venía derrotado de gente porque los enemigos se la habían muerto, pero él también había hecho muchas muertes, y adquirido la fama de bravo". ${ }^{25}$ Su nombre hace referencia, como en 1678 en Buenos Aires, a un cacique en conflicto con otros de la tierra adentro.

El análisis de los nombres de los caciques registrados en estas fuentes documentales nos ofrece algunos indicios sobre la población originaria de la región pampeana. En primer lugar, como lo afirmó Caballero para Ignacio, Bravo y Manuel, ${ }^{26}$ algunos otros individuos podrían estar emparentados entre sí. Asimismo, la reiteración de los nombres podría indicar territorialidades y/o itinerarios compartidos para estos caciques, al menos en las cercanías de Melincué en 1677 cuando fueron apresados y a principios de 1690 en el río Cuarto cuando se encontraron con Caballero. ${ }^{27}$ Además, la repetición de las denominaciones también puede deberse a estrategias de los colonizadores para controlar a la población indígena ya que se trata en la mayoría de los casos de nombres españoles y no en lengua indígena, que en general desconocemos. Por ejemplo, sabemos que Bravo se llamaba de otra manera -ya que así figura en la documentación donde se describió su primer encuentro con los funcionarios- pero su nombre Nusanash fue apartado a favor del apelativo "Bravo" otorgado por los hispanocriollos. ${ }^{28}$

Asimismo, la reiteración de ciertos nombres a lo largo de estas décadas en la misma región también puede deberse a estrategias de los grupos indígenas utilizadas en función de sus propios intereses políticos. En este sentido, Bechis (2006) observó cómo las sociedades indígenas se apropiaron de ideas y términos empleados por los agentes coloniales y los integraron y recrearon en beneficio propio. En relación con esto y siguiendo la propuesta de Boccara (2003: 91), debemos "reconocer que las identidades están siempre en movimiento y dependen del contexto, del momento de la vida social y de la naturaleza del contacto". Por lo tanto, el análisis de los alias de los caciques nos permite observar a nivel individual las prácticas de control implementadas por los funcionarios coloniales. Creemos que, del mismo modo que el empleo de rótulos para designar a grupos indígenas se corresponde con categorías que fueron impuestas, este fenómeno pudo haberse repetido a nivel de identificaciones
23. AGl. ACH, Leg. 283, carta de Don José de Herrera y Sotomayor, Ciudad de la Trinidad puerto de Buenos Aires, 23/08/1686. Hay copia en el ME, carpeta G, doc. 29.

24. AGI. ACH, Leg. 283, carta de Don José de Herrera y Sotomayor, Ciudad de la Trinidad puerto de Buenos Aires, 30/o8/1686. Hay copia en el ME, carpeta G, doc. 29.

25. AGN, leg. 189, doc. 1845, "La misión de los Pampas" por el P. Lucas Caballero, f. 93 (en Page, 2007: 434).

26. Si bien hay algunas diferencias en los nombres -Don Manuel/ Don Manuel Flaco y Don Ignacio/ Don Ignacio Jalamelec/ Don Ignacio Muturo-, creemos que podría tratarse de las mismas personas.

27. Aunque en Buenos Aires -donde fueron empadronados- y en Santo Domingo Soriano -hacia donde fueron trasladados- también figuran juntos estos caciques, se trató de traslados compulsivos, que no respondieron a itinerarios propios de los caciques y sus grupos.

28. En un trabajo anterior nos hemos referido a los nombres de los caciques que podemos encontrar en los diarios de operaciones; señalamos lo llamativo de la existencia de un "cacique Julián en las proximidades de la bahía de San Julián" y de "un cacique Negro en las inmediaciones del río del mismo nombre" (Nacuzzi et al., 2018: 87) 
individuales. Los funcionarios coloniales en pocos casos utilizaron los nombres propios de los caciques en lenguas indígenas ya que optaron por asignarles alias nuevos en castellano y en función de su propia cosmovisión del mundo.

\section{Los rótulos en perspectiva histórica y geográfica}

Hallamos algunas diferencias en las menciones a los caciques y a sus grupos según escribiera el jesuita Caballero desde Córdoba o los funcionarios coloniales desde Buenos Aires. En el sur de Córdoba, todos los caciques mencionados fueron identificados como pampas mientras que en Buenos Aires se utilizaban alternativamente los rótulos pampas y serranos sumados a algunos otros como tubichaminís y baguales. En este sentido, según Pedrotta (2005), las denominaciones pampas y serranos empleadas a partir del siglo XVII para referirse a las sociedades indígenas que habitaban la región pampeana estaban vinculadas al ambiente habitado o frecuentado por dichos grupos: las extensas planicies o pampas y las zonas serranas.

Además, estas categorías no eran fijas sino que dependían de quién registraba en el caso de los padrones o de quién elaborara los documentos y desde qué lugar geográfico se llevaran a cabo estas acciones. En palabras de Roulet (2016: 51), se trata de "designaciones cambiantes, cargadas de sentidos e históricamente construidas [que] reflejan un panorama sumamente dinámico en el que se producen toda clase de fenómenos de reconfiguración y reinterpretación étnica, potenciados por la intervención colonial". A modo de ejemplo, en 1686 los caciques Bravo, Ignacio y Sacaperu se encontraban en Santo Domingo Soriano donde fueron denominados pampas, serranos, pampas serranos y serranos pampas dependiendo de quién escribiera. Las mayores referencias al cacique Sacaperu como serrano provienen de los funcionarios coloniales que se refirieron a él desde Buenos Aires y desde Santo Domingo Soriano, entre ellos, los que lo llevaron junto con sus seguidores hacia la reducción. Las referencias a Bravo como un cacique pampa y/o serrano también fueron dichas por los funcionarios que se refirieron a él así como por una declarante que dijo "ser de nación serrana sujeta a la parcialidad del cacique Bravo". Por su parte, Ignacio también fue identificado como serrano por otra mujer "de nación sujeta al cacique Don Ignacio serrana como lo es la declarante". ${ }^{30} \mathrm{Si}$ bien la mayoría de las referencias a los caciques son como serranos, también hay algunas que los identifican como pampas, como por ejemplo Sacaperu, quien fue identificado por esta última declarante como "de nación pampa".

[de Yapiquene], Buenos Aires, 23/og/1686. Hay copia en el ME, carpeta $\mathrm{G}$, doc. 29.

31. AGl. ACH, Leg. 283, declaración [de Yapiquene], Buenos Aires, 23/09/1686. Hay copia en el ME, carpeta G, doc. 29 .

32. AGI. ACH, Leg. 283, carta de don Francisco Izquierdo al gobernador y capitán general, Santa Fé, 07/09/1686. Hay copia en el ME, carpeta G, doc. 29.
Por otro lado, al referirse a quienes habían causado las muertes de manera general, sin focalizar en los caciques, la mayoría de las veces las menciones apuntaban a que los culpables habían sido los grupos "pampas y serranos", "serranos y pampas", "pampas serranos" o "serranos pampas" recientemente trasladados a la reducción. Como mencionamos previamente, los rótulos aludían a identidades impuestas, otorgadas "a grandes rasgos, por ubicación geográfica, relaciones con otros grupos" donde lo principal para los agentes de la colonia era "hacer posible la convivencia y el trato con ellos" sin "delimitar grupos y naciones" (Nacuzzi, 1998: 133). En el caso de los rótulos otorgados a los grupos indígenas trasladados a Santo Domingo Soriano resulta ilustrativo que las únicas menciones a ellos como pampas -"los dichos pampas" y "los indios pampas" ${ }_{-}$, , sin el agregado de serranos, fueron realizadas por un funcionario desde la ciudad de Santa Fe. 
Por este motivo, creemos que las referencias de Caballero al identificar a todos los caciques como pampas no sería un impedimento para encontrar a los mismos grupos en las mismas $u$ otras zonas designados bajo un rótulo distinto. Según Giudicelli (2007: 179, cursiva en el original), debemos realizar "un microanálisis y un seguimiento cronológico" para acceder "a la comprensión de las divisiones operadas en la época colonial y a la lógica que presidía las relaciones entre varias parcialidades independientemente de las denominaciones españolas".

Además de las coincidencias en los nombres de los caciques que circularon en la segunda mitad del siglo XVII en la zona del río Cuarto y -de manera forzadaen las cercanías del Río de la Plata, la relación escrita por el jesuita Caballero también brinda otras conexiones entre los habitantes de la llanura pampeana. En una de las conversaciones entre Ignacio y Caballero, el cacique se refirió a las pestes de viruela que los habían asolado en Areco, cuando "se juntaron aquí con su corregidor más de trescientos pampas" ${ }^{\prime{ }^{33}}$-en alusión a la reducción del Bagual. Los grupos indígenas que allí habían sido relocalizados fueron identificados como mbeguás y querandíes (Carlón, 2006), como se designó a los grupos aledaños a la ciudad de Buenos Aires en los primeros tiempos de la conquista, rótulos que luego dejaron de ser empleados en las fuentes. Los lugares destinados a estas primeras reducciones fueron reutilizados durante el transcurso del siglo XVII para trasladar a grupos indígenas apresados en la tierra adentro, como por ejemplo por Andrés de Robles en 1676, cuando “pasó a los parajes donde estaban sus toldos a treinta y cuarenta leguas de la ciudad" y "recogió a todos sin ausentarse ninguno, en número de cerca de ocho mil almas de todos sexos y edades ${ }^{\prime{ }^{34}}$ y los situó en la laguna de Aguirre -a ocho leguas de la ciudad-, sobre el río Luján -a diez leguas- y "sobre el río de Areco, que llaman el Baguan, sitio propio suyo". ${ }^{35}$ Sin embargo, como también recordó el cacique, en ese entonces

los sobrevino una peste de viruela con tal rigor que se morían los más, con que pidieron licencia muchos de ellos, ofreciendo volver, y como la mortandad era tanta y detenerlos por fuerza imposible, y que de no dársela se habían de huir tuvo por conveniente concedérsela.

Observamos, así, que el cacique Ignacio nos permite establecer una continuidad entre los grupos trasladados de manera compulsiva hacia el río Areco a principios del siglo XVII -luego diseminados debido a la viruela- y la población indígena que se encontraba en el río Cuarto unas décadas más tarde. La identificación de los grupos reducidos como mbeguás y querandíes a diferencia de los del río Cuarto, reconocidos como pampas, está relacionada con divergencias en las categorías empleadas para rotular por parte de los agentes coloniales por lo que no implica que se tratara de grupos distintos. Incluso, sabemos que hacia principios del siglo XVIII en la frontera bonaerense eran designados pampas

a quienes se suponía descendientes de los querandíes de tiempos de la conquista -los baguales, tubichaminís, caguanés y vilachichis- así como a distintos pueblos de origen serrano, cordillerano, patagónico e incluso trasandino instalados en la llanura" (Roulet, 2016: 65).

En términos de Boccara, los funcionarios coloniales clasificaron y ordenaron a los pueblos originarios a lo largo de las décadas de forma tal que, para el siglo XVII, el fenómeno de etnificación había creado dos entidades étnicas: pampas y serranos. Sin embargo, estas categorías no designaban a grupos determinados
33. AGN, leg. 189 , doc. 1845 , “La misión de los Pampas” por el P. Lucas Caballero, f. 94 (en Page, 2007: 440).

34. Según Bechis (2008b), es probable que el número 8.000 sea exagerado o se trate de un error de imprenta.

35. AGI. Audiencia de Buenos Aires (en adelante AB), leg. 3, carta del Rey al Gobernador de Buenos Aires, Madrid, 16/08/1679. Hay copia en el $\mathrm{ME}$, carpeta F, doc. 14 .

36. AGI. AB, leg.3, carta del Rey al Gobernador de Buenos Aires, Madrid, 16/08/1679. Hay copia en el ME, carpeta F, doc. 14 
sino que se empleaban de manera flexible. Se trata de rótulos que aluden, como ya vimos, a estrategias implementadas por el sector colonial para clasificar a los pueblos originarios en base a criterios funcionales a sus intereses, no obstante lo cual también reflejan "las luchas de clasificación" (Boccara, 2002: 52) de los grupos sociales, en este caso desde una perspectiva étnica. Por esto, creemos que es conveniente atender a los cambios de denominación de los grupos en tanto estrategias coloniales pero también como estrategias indígenas.

\section{Consideraciones finales}

En este trabajo nos centramos en algunos aspectos de los grupos indígenas que habitaron en la llanura pampeana en la segunda mitad del siglo XVII. Particularmente, focalizamos en los registros escritos elaborados por algunos agentes coloniales que exploraron la región desde las ciudades de Buenos Aires y de Córdoba. Para el análisis de las fuentes seguimos los postulados de Nacuzzi (1998), Giudicelli (2007) y Roulet (2016) quienes advirtieron sobre la influencia de la perspectiva de quienes registraron a la población originaria en los corpus documentales. De esta manera, observamos que tanto los nombres propios de los caciques como los rótulos asignados a ellos junto con los grupos que los acompañaban estaban relacionados con la región desde la cual se escribía, la información disponible sobre ellos y las necesidades que guiaban a los agentes a la hora de elaborar los documentos escritos.

En el caso presentado, observamos cómo las denominaciones de los caciques fueron modificadas continuamente a partir de diversos mecanismos que consistieron, por ejemplo, en reemplazar sus nombres indígenas -Nusanash- por alias españoles -Bravo- o en modificar una parte de sus nombres -Ignacio- al agregarle la "nación" con la que lo identificaban en ese momento -Jalamelec. Notamos la reiteración de estos nombres en diversos lugares y fechas por lo que nos preguntamos si se trataría de indicios de la movilidad de los caciques y sus seguidores o si serían mecanismos de la colonia para identificar a un "otro"y/o de estrategias de los grupos indígenas para presentarse ante un "otro". En cualquier caso, formaron parte de las transformaciones identitarias que se generaron a partir de las relaciones entabladas entre las sociedades indígenas y las hispanocriollas en las cuales los nombres indígenas fueron desplazados a favor de los alias o apodos españoles. Eso no quita que, por un lado, pudieran haber continuado con el uso de sus nombres -sin que los funcionarios y misioneros lo registraran- así como variando de nombre en función del interlocutor, como una estrategia política.

Por otro lado, identificamos algunas conexiones entre parajes de la zona que nos permitieron aproximarnos a los itinerarios seguidos por los grupos en cuestión. Los puestos conocidos como Espinillo y Punta del Sauce en el río Cuarto -en la región al sur de la ciudad de Córdoba- y el paraje de Melincué -a mitad de camino entre Córdoba y Buenos Aires- formaron parte del territorio habitado por los grupos indígenas de la región pampeana. Asimismo, los desplazamientos forzados hacia las reducciones aledañas a la ciudad de Buenos Aires -Bagual en el río Areco y Santo Domingo Soriano en el río Uruguay- y hacia las encomiendas cercanas a la ciudad de Córdoba nos permitieron analizar los registros elaborados por los funcionarios coloniales y la información de los grupos indígenas de la zona. Por lo tanto, la región que abarcaba estos parajes y los territorios comprendidos entre ellas estuvo habitada por los grupos conocidos como pampas y serranos, ya fuera por las características 
propias de su movilidad o debido a las modificaciones de los asentamientos implementadas por la colonia.

Como analizamos a lo largo del trabajo, las diferencias en los rótulos empleados para denominar a estos grupos -a veces serranos, otras pampas- se relacionaron con las localizaciones de los grupos y las intenciones de quienes elaboraron los registros escritos y no con diferencias en los grupos observados. Así, a partir del análisis del derrotero de estos sujetos -a nivel individual y grupal- creemos que, además del uso alternativo de los rótulos pampas y serranos en los alrededores de Buenos Aires, también se utilizaba la denominación de pampas en las cercanías de Córdoba para aludir a los mismos grupos. En futuros trabajos, esperamos continuar el análisis de estos indicadores para lograr profundizar en el conocimiento de los pueblos indígenas de la región pampeana. 


\section{Q Fuentes documentales}

" Archivo General de Indias (AGl), Audiencia de Charcas (ACH), legajos 283 y 284. Copias del Museo Etnográfico "Juan B. Ambrosetti" (ME), Facultad de Filosofía y Letras, Universidad de Buenos Aires, carpetas F y G.

"Archivo General de Indias (AGI), Audiencia de Buenos Aires, legajo 3. Copias del Museo Etnográfico "Juan B. Ambrosetti” (ME), Facultad de Filosofía y Letras, Universidad de Buenos Aires, carpeta F.

»Archivo General de la Nación (AGN), legajo 189, documento 1845, folios 88-107. En Page, C. (2007).

» Biblioteca Nacional de Río de Janeiro, rollo 36, documento 1093, imágenes 399 a 447. 


\section{Q Bibliografía}

"Arias, F. (2011-2012). Fronteras interétnicas en el espacio de las pampas durante la primera mitad del siglo XVIII: el caso del linaje de los caciques Bravos y sus relaciones interregionales. Anuario 24, Escuela de Historia: 121-146.

»Assadourian, C. (1982). "Economías regionales y mercado interno colonial: el caso de Córdoba en los siglos XVI y XVII" en El sistema de la economía colonial. Mercado interno, regiones y espacio económico: 18-55. Lima, Instituto de Estudios Peruanos.

"Assadourian, C., Beato, G. yJ. Chiaramonte (2005). Historia Argentina 2. De la conquista a la independencia. Buenos Aires, Paidós.

" Barrionuevo Imposti, V. (1986). Historia de Río Cuarto. En la época Hispánica y en la Independencia. Tomo I. Buenos Aires, TIPENC SRL.

» Bartolomé, M. A. (2003). Los pobladores del "Desierto" genocidio, etnocidio y etnogénesis en la Argentina. Cuadernos de Antropología Social 17: 162-189.

" Bartolomé, M. A. (2006). As etnogêneses: Velhos atores e novos papéis no cenário cultural e político. MANA 12 (1): 39-68.

» Bechis, M. (2006). La 'organización nacional' y las tribus pampeanas en Argentina durante el siglo XIX. TEFROS 4 (2): 1-24.

" Bechis, M. (2008a). "Ángulos y aristas de la guerra por las vacas en los comienzos del siglo XVIII: "divertimentos", asesinatos y rivalidades jurisdiccionales" en Bechis, M., Piezas de Etnohistoria del sur sudamericano: 53-80. Madrid, CSIC.

» Bechis, M. (2008b). “Pensar la paz: pampas, serranos, puelches y aucas a propósito del tratado de paz entre la gobernación de Buenos Aires y el cacique tehuelche-serrano Cangapol (1740-1742)" en Bechis, M., Piezas de Etnohistoria del sur sudamericano: 82-113. Madrid, CSIC.

"Boccara, G. (2002). “Colonización, resistencia y etnogénesis en las fronteras americanas" en Boccara, G (ed.), Colonización, resistencia y mestizaje en las Américas siglos XVI-XX: 4782. Lima/ Quito, IFEA/ Abya Yala.

" Boccara, G. (2003). “Fronteras, mestizaje y etnogénesis en las Américas” en Mandrini, R y C. Paz (comps.), Las fronteras hispanocriollas del mundo indígena latinoamericano en los siglos XVIII-XIX: 63-108. Neuquén/ Bahía Blanca/ Tandil, CEHIR/UNS/ IEHS.

"Carlón, F. (2006). Políticas correctivas del comportamiento social indígena y formas de resistencia en las reducciones de Baradero, Tubichaminí y del Bagual (primeras décadas del siglo XVII). Mundo Agrario 7 (13). Disponible en Internet: http://www.memoria.fahce. unlp.edu.ar/art_revistas/pr.511/pr.511.pdf Consultada el: 25 de junio de 2018.

"Castro Olañeta, I. (2005). La cédula de encomienda a favor de Don Gerónimo Luis de Cabrera. Copias y traslados de un mismo documento durante los siglos XVI y XVII. Cuadernos de Historia, Serie Ec. y Soc. 7: 215-233.

» Fradkin, R. yJ. C. Garavaglia (2009). La Argentina colonial. El Río de la Plata entre los siglos XVI y XIX. Buenos Aires, Siglo Veintiuno Editores.

"Giudicelli, C. (2007). Encasillar la frontera. Clasificaciones coloniales y disciplinamiento del espacio en el área diaguito-calchaquí, siglos XVI-XVII. Anuario IEHS 22: 161-211.

"Lorandi, A. (2008). Poder central, poder local: Funcionarios borbónicos en el Tucumán colonial, un estudio de antropología política. Buenos Aires, Prometeo. 
" Nacuzzi, L. (1998). Identidades impuestas. Tehuelches, aucas y pampas en el norte de la Patagonia. Buenos Aires, Sociedad Argentina de Antropología.

» Nacuzzi, L. (2014). Los caciques amigos y los espacios de la frontera sur de Buenos Aires en el Siglo XVIII. TEFROS XII (2): 103-139.

» Nacuzzi, L. (2016). “El “indio Flamenco”: líder mestizo de la frontera sur en el siglo XVIII. Un aporte a la discusión sobre los rótulos étnicos. Fronteras de la Historia 21 (1): 38-63.

» Nacuzzi, L. y L. Tourres (2018). “Acuerdos del cabildo de Buenos Aires” en Nacuzzi, L. (coord.), Entre los datos y los formatos: indicios para la historia indígena de las fronteras en los archivos coloniales: 29-68. Buenos Aires, Centro de Antropología Social-IDES.

» Nacuzzi, L., Enrique, L. A. y S. Vollweiler (2018). "Diarios de operaciones de las expediciones hacia la tierra adentro" en Nacuzzi, L. (coord.), Entre los datos y los formatos: indicios para la historia indígena de las fronteras en los archivos coloniales: 69-115. Buenos Aires, Centro de Antropología Social-IDES.

» Page, C. (2006). El padre Francisco Lucas Cavallero y su primera experiencia misional con la reducción de indios pampas. Revista de Humanidades y Ciencias Sociales 12 (1): 243-264.

»Page, C. (2007). La relación del P. Francisco Lucas Cavallero sobre la formación de la reducción jesuítica de indios pampas en Córdoba (15-07-1693). Revista de la Junta Provincial de Historia de Córdoba (Segunda época): 429-454.

»Palomeque, S. (200o). “El mundo indígena. Siglos XVI-XVIII” en Tandeter, E (ed.), Nueva Historia Argentina. La sociedad Colonial, Tomo 2: 87-144. Buenos Aires, Sudamericana.

»Pedrotta, V. (2005). Las sociedades indígenas del centro de la provincia de Buenos Aires entre los siglos XVI y XIX, Facultad de Ciencias Naturales y Museo, Universidad de La Plata. Trabajo de tesis para optar por el título de Doctor en Ciencias Naturales.

»Pérez Zavala, G. y M. Tamagnini (2012). Dinámica territorial y poblacional en el Virreinato del Río de la Plata: indígenas y cristianos en la frontera sur de la gobernación intendencia de Córdoba del Tucumán, 1779-1804. Fronteras de la Historia 17 (1): 195-225.

» Roulet, F. (2016). Huincas en tierra de indios. Mediaciones e identidades en los relatos de viajeros tardocoloniales. Ciudad Autónoma de Buenos Aires, Eudeba.

» Roulet, F. (2018). Violencia indígena en el Río de la Plata durante el período colonial temprano: un intento de explicación. Nuevo Mundo Mundos Nuevos. Disponible en internet: https://journals.openedition.org/nuevomundo/72018. Consultada el: 12 de diciembre de 2018.

» Salles, E. y H. Noejovich (1999). Santiago y Buenos Aires: la actividad económica en la frontera sur del virreinato del Perú en el siglo XVII. Economía, 22 (43): 183-220.

» Simonassi, M. R. (2016). Abriendo fronteras en el sur cordobés: el cacique Ignacio Muturo y el padre Francisco Lucas Caballero: la presencia jesuítica en el Río Cuarto y la primera reducción de pampas a fines del siglo XVII. Tesis de Licenciatura Especializada en Historia de la Iglesia, Universidad Católica Argentina. Facultad de Teología. Disponible en internet: http://bibliotecadigital.uca.edu.ar/repositorio/tesis/abriendo-fronterassur-cordobes.pdf. Consultado el: 3 de marzo de 2019.

» Tapia, A., Néspolo, E. y V. Noya (2015). Origen y evolución del pueblo de indios de Baradero, según documentos del siglo XVII y XVIII en Santiago del Baradero. Origen y evolución del pueblo de indios. Documentos del Archivo General de Indias (siglos XVII y XVIII). Buenos Aires, Pangea Ediciones de la Tierra. Disponible en internet: https://www. academia.edu/37465060/ Consultada el: 23 de septiembre de 2018.

" Trujillo, O. (2014). Los gobernadores de Buenos Aires a mediados del siglo XVII: mediación y conflicto en los confines de la monarquía hispánica. História, histórias 2 (3): 92-108. 